\title{
Acceptable Behavior or Workplace Bullying?-How Perpetrator Gender and Hierarchical Status Affect Third Parties' Attributions and Moral Judgments of Negative Behaviors
}

\author{
Eva Zedlacher ${ }^{1, *}$ and Denise Salin ${ }^{2}$ (D) \\ 1 Department of Business and Management, Webster Vienna Private University, 1020 Vienna, Austria \\ 2 Department of Management and Organization, Hanken School of Economics, 00100 Helsinki, Finland; \\ denise.salin@hanken.fi \\ * Correspondence: eva.zedlacher@webster.ac.at
}

check for

updates

Citation: Zedlacher, E.; Salin, D. Acceptable Behavior or Workplace Bullying?-How Perpetrator Gender and Hierarchical Status Affect Third Parties' Attributions and Moral Judgments of Negative Behaviors. Societies 2021, 11, 62. https:// doi.org/10.3390/soc11020062

Academic Editors: Margaret Hodgins and Patricia Mannix McNamara

Received: 1 May 2021

Accepted: 31 May 2021

Published: 16 June 2021

Publisher's Note: MDPI stays neutral with regard to jurisdictional claims in published maps and institutional affiliations.

Copyright: (C) 2021 by the authors. Licensee MDPI, Basel, Switzerland. This article is an open access article distributed under the terms and conditions of the Creative Commons Attribution (CC BY) license (https:// creativecommons.org/licenses/by/ $4.0 /)$.

\begin{abstract}
Workplace bullying consists of repeated, long-term exposure to a variety of negative behaviors. However, it remains unclear when behaviors are seen as morally acceptable vs. become bullying. Moral judgments affect whether third parties deem it necessary to intervene. In this qualitative study, we first conceptualize and then explore via 27 interviews with Austrian HR professionals and employee representatives whether twelve diverse negative behaviors elicit distinct causal attributions and moral judgments. In particular, we examine how a perpetrator's hierarchical position and gender shape the third parties' evaluations. A qualitative content analysis reveals the behaviors vary in their perceived acceptability and associations with workplace bullying. Ambiguous behaviors require specific cues such a perpetrator's malicious intent to be labeled workplace bullying. Overall, third parties judge behaviors by supervisors more harshly, particularly when managerial role expectations are violated. The majority of informants reject the notion that their perceptions are affected by perpetrator gender. Still, women who engage in behaviors associated with anger or a lack of empathy are often perceived as acting with intent. The findings suggest that the violation of social role expectations amplifies the attribution of dispositional causes (e.g., malicious intent). We discuss the relevance of perpetrator intent for research and practice.
\end{abstract}

Keywords: workplace bullying; moral judgments; attributions of intent; perpetrator status; perpetrator gender; ethical decision making

\section{Introduction}

Researchers usually measure exposure to the phenomenon of workplace bullying via behavioral checklists. Repeated, long-term exposure to at least one or two negative behaviors by supervisors, peers, or subordinates indicates severe victimization [1,2]. The negative behaviors may include person-related behaviors such as yelling or spreading rumors; work-related behaviors such as persistent criticism or withholding important information; and behaviors of social exclusion such as ignoring someone or performing practical jokes [2]. However, particular work-related behaviors like persistent criticism are often considered legitimate managerial practices by HR professionals [3,4], i.e., they are then not attributed to a malicious perpetrator intent.

However, it remains under-researched how the hierarchical status of a perpetrator (e.g., supervisor vs. peer) "normalizes" or aggravates third-party evaluations of (ambiguous) behaviors. In addition, there is a lack of conceptual and empirical studies which investigate how other social roles such as gender may affect third parties' attributions and labeling of negative behaviors as acceptable vs. workplace bullying. For example, we propose that highly anti-communal behaviors such as physical violence or screaming will be interpreted more negatively when performed by female perpetrators since the behaviors disconfirm gender stereotypes. 
In this qualitative study we aim to conceptualize and then investigate via 27 interviews with Austrian HR professionals and employee representatives how and to what extent gender and the hierarchical status of the person performing a negative behaviour can influence attributions and moral judgments of third parties. To do so, we present 12 different "typical" negative workplace behaviors to informants. We explore via a qualitative content analysis how informants arrive at their moral judgments and how their (primary) attributions and the social role affected the labeling of a behavior as "acceptable" or "workplace bullying".

This study sets itself apart from the "European tradition" of workplace bullying research by going beyond a narrow focus on targets' perceptions and victimization processes. To the authors' best knowledge, the impact of perpetrator characteristics on conceptualizations of workplace bullying has not yet been scrutinized from the perspective of attribution theory [5,6] or recent social-intuitionist approaches in moral psychology [7]. Examining the perspectives of different organizational third parties also has great practical relevance: not only are human resources professionals and employee representatives in charge of prevention, these non-observing third parties often also have the prerogative of interpretation, as they can decide whether a target's complaint is workplace bullying or not.

In the following sections we first review third-party conceptualizations of negative behaviors and workplace bullying and then shed light on how gender and hierarchical status may affect the moral judgments and attributions of blame. We then present our study design, results, and discussion in detail.

\subsection{Evaluating Negative Behaviors from a Third-Party Perspective}

Heinz Leymann, a Swedish psychiatrist of German origin and a pioneer of bullying research, defined bullying and proposed four key features of "mobbing" [1]. These features still constitute the defining criteria of workplace bullying from the European perspective. The first defining feature is exposure to a variety of negative behaviors of a mostly psychological nature, with only a few reports of physical violence or sexual harassment. Often, these behaviors are further classified into work-related (e.g., constant criticism of a person's performance, withholding information) and person-related behaviors (e.g., gossiping behind a person's back, yelling) [8,9].

Some authors regard behaviors entailing social exclusion ("non-behaviors" such as ignoring or excluding someone) and/or physical violence as additional categories, while others regard these as separate categories [2,3]. To be labeled workplace bullying, the behaviors must occur repeatedly (at least weekly) and over a long period of time (usually more than six months). As such, workplace bullying is less about the content, intensity, or severity of a single act. Rather, it is the continuous exposure to (low-intensity) behaviors that over time makes targets feel powerless to defend themselves [1]. This perceived power imbalance distinguishes bullying from "normal" conflicts and other constructs like incivility.

Negative behaviors involving emotional abuse and social marginalization, such as humiliating, ridiculing, insulting, or spreading rumors about someone, were considered the most severe in a Spanish sample encompassing targets, witnesses, and non-observing third parties [8]. Supervisors are more often reported as bullies than peers or subordinates. Overall, men are reported as perpetrators more often than women [10].

In academic research, workplace bullying is typically defined according to the four criteria listed above. However, empirical evidence from the Anglo-American context indicates that organizational third parties are often reluctant to name employees' complaints "workplace bullying" [4,11]. Cowan [12] showed that HR professionals engage in sensemaking when faced with ambiguous behaviors and search for external verification of cues like severe outcomes and/or malicious intent to harm the target by the perpetrator before labeling a given complaint bullying [3,12-14]. The nature of the hierarchical relationship between perpetrator and target might strongly shape third-party sensemaking and associations with workplace bullying: supervisory bullying has been trivialized as "bad leadership" or "managerial prerogative", as third parties often automatically assume 
that underperformance by the target is the underlying cause $[3,4,11,15]$. To the best knowledge of the authors, no empirical research has been conducted on how the gender of a perpetrator might affect the (causal) attributions and labeling of a behavior.

\subsection{How Perpetrators' Social Roles Affect Moral Judgments by Third Parties}

Most existing (psychological) approaches to moral responsibility ignore the sociocultural context in which the perpetrator's conduct is embedded [16]. Attribution theory suggests that the more a behavior fails to conform to role and situational expectations at work, the more likely it will be attributed to the perpetrator's "malicious" disposition and intent [5]. Any social or organizational role encompasses both descriptive and normative behavioral expectations by members of the respective group [17]. Accordingly, we propose that third parties' moral judgments are influenced not only by their (tacit) understanding of how people in certain roles usually behave, but also how they should behave in a work context. Before we conceptualize the influence of two roles (hierarchical status and gender of the perpetrator) on moral judgments and attributions, we review other factors impacting the moral judgments of a behavior.

\subsection{Moral Judgments}

Making a moral judgment requires, first and foremost, moral awareness. If organizational third parties do not consider a negative behavior a moral issue, they will not judge it negatively and eventually will not intervene (ethical decision-making framework) [18,19].

Moral judgments can be fast and emotional or the result of a deliberate cognitive process. We propose that behaviors which severely violate established workplace norms (e.g., physical violence against other employees) will elicit moral intuition ("This is just wrong") [7] and quick deontic responses, i.e., the act should/ought not be performed as it violates established fairness norms at the workplace $[7,20,21]$. Conversely, a negative behavior could be associated with potentially positive causes (e.g., a supervisor trying to support the target via criticism) and outcomes (e.g., complying with organizational and performance requirements). Hence, in particular for work-related behaviors the moral reasoning process might be longer [21,22].

However, not every evaluation might elicit a blame judgment against a perpetrator [23]. Assigning blame for an act usually involves sensemaking in the form of (causal) attributions: was the act caused solely by the perpetrator, was the act controllable and/or intended, was the act immoral and/or its outcome severe? [21,23-27]. The belief that the negative act has its origin in the perpetrator's mental state of free will (i.e., malicious intent) to severely harm the target is central to blame attributions [23,25,26,28-30]. Attributing intent implies believing that the perpetrator had a plan, that he/she foresaw the link between his/her action and the harmful outcome [23,25,31]. People are more inclined to say (retrospectively) that an act was performed intentionally when they consider that act to be morally wrong [32], severe and harmful [33], and/or when the act resulted in foreseeable negative (side) effects [32]. Hence, behaviors such as physical violence may elicit attributions of perpetrator agency and blaming more than others due to the foreseeable harm and moral intensity they involve.

Third parties usually find reasons that explain or mitigate the perpetrator's underlying intent [34]. Reasons such as pursuing one's own selfish goals, revenge, or taking pleasure in harming others imply malicious intent and violate deontic norms. Attributions of benevolence, thoughtlessness, or a higher moral cause or goal mitigate intent $[7,23,29]$. Even when a perpetrator is attributed to act with intent, the attribution of stable, uncontrollable dispositions, mental states, habits or reflexes, or a lack of cognitive capacity to control or prevent a behavior might reduce the perpetrator's blameworthiness [7,28,29]. Moreover, external situational requirements (e.g., organizational restructuring) might affect the perceived controllability of a (work-related) negative behavior by the perpetrator (e.g., removing key areas of responsibility) and thus reduce blame. Furthermore, although the perpetrator engages in the behavior, the target might be found culpable: if a target is 
believed to be underperforming due to low effort rather than a stable, uncontrollable low level of ability, negative perpetrator behavior such as persistent criticism is more likely to be excused $[7,29]$.

The search for causality is also influenced by the information available to the third party [5]. The factors of consistency (perpetrator exhibits the same behavior in different situations), distinctiveness (singling out; perpetrator exhibits the behavior only toward one specific person), and consensus (other people at the workplace exhibit the same behavior) are likely to affect third-party attributions of causes [5,35].

We propose that high consistency and distinctiveness may increase attributions of internal causes (e.g., the perpetrator's malicious disposition) to a negative behavior and thus perceptions of workplace bullying. However, if the behavior can be justified with external causes (e.g., job requirements or employee's low performance), external attributions of blame are more likely. Moreover, high consensus (e.g., seeing a behavior as "common practice" in the organization or in workgroup interactions) will make the behavior seem more acceptable and thus tend to excuse the perpetrator's behavior.

\subsection{How the Hierarchical Status of a Perpetrator Influences Moral Judgments}

A hierarchical difference can result from differences in status (admiration and respect) or in power, defined as "asymmetric control over valued resources in social relations" [36]. Third parties' interpretations might be sensitive to the (hierarchical) relationship between the perpetrator and the target. First, negative behaviors by supervisors might be judged more negatively due to the potentially more severe outcomes of a supervisor's actions. For both targets and third parties, ambiguous negative behaviors committed by supervisors with higher formal power may be more distressing due to possible sanctions in the case of resistance [37]. Second, perpetrators with higher hierarchical status are held to a higher moral standard due to role expectations. Role expectations for supervisors include distributing resources fairly and focusing on attaining group and organizational goals to a higher extent than "normal" employees. In other words, supervisors are expected to model expected behavior for their subordinates [37,38]. In Haidt and Baron's [39] experimental study in the US, both behaviors of omission (e.g., withholding information) and "active" behaviors were judged more harshly when conducted by people in positions of authority than by people with less responsibility. Thus, when a supervisor violates expectations, it could lead to deontic responses or beliefs that the supervisor could/should/ought to have acted differently to prevent the behavior or the outcome $[16,20,23,40]$. Hence, we propose that supervisors will generally be judged more severely than peers or subordinates for negative behavior, unless the behavior conforms to managerial role expectations in performance-driven business cultures (e.g., persistent criticism of low-performing targets). Engaging in negative behaviors and expressing negative emotions might be judged as even less acceptable in cultures with low power distance, in which supervisors' abuse of (formal) power may be considered reprehensible [41]. Moreover, Sloan [42] argues that while a "neutral" expression of emotions is permissible in many professional occupations, supervisors' higher hierarchical status may make it more acceptable for them to express negative behaviors associated with anger. This is at least partly because the free expression of anger is often associated with a higher status, masculinity, and power [12,43-45].

\subsection{How the Gender of a Perpetrator Influences Moral Judgments}

We claim that many gendered perceptions of perpetrator behavior stem from traditional beliefs about gender differences in emotional intensity and expressivity. As women often occupy low-status roles and jobs in which they are required to display caring and service-oriented attitudes, perceivers may assume that women not only possess corresponding dispositions, but that they also should be more communal, socially competent, warm, and "emotional" [17,42]. Also, men are believed to have a higher propensity to engage in overt person-related aggression (e.g., violence, screaming) because they often have a hostile attributional style; gender differences for work-related behaviors might be 
less pronounced [46]. In contrast, women are stereotypically attributed higher empathy levels, greater emotional intensity, and greater sensitivity to the nuances of others' behavior $[44,45]$. While the existence of gender differences regarding the frequency of such emotional experiences have been called into question, women are expected and found to be more "emotionally expressive" than men $[41,46,47]$. This greater acceptance of emotional expression often leads to the stereotype that women are less able to control their emotions and are at higher risk of having their emotions influence their thoughts and behaviors [43]. In contrast, traditional gender stereotypes depict men as engaging in behaviors involving agency (i.e., being aggressive, ambitious, dominant, and independent). Men are also stereotypically considered to be less emotionally intense and more in control of their positive and negative emotions, with two exceptions: anger and pride are considered acceptable emotions for men at work $[12,45,48]$. When men display anger, it is considered an indicator of power and may even lead to more respect and fear; in contrast, angry women are often judged as complainers or as being too emotional and lacking a communal orientation [43].

It is known from sexual harassment research that female targets whose behavior does not conform to traditional gender stereotypes (e.g., because they are "too" agentic and assertive) are often attributed even more blame than those who conform to stereotypical role expectations [49]. Cultural values such as low gender egalitarianism and a high level of assertiveness practices [41] (a dimension which resembles Hofstede's masculinity index) might make a stereotypical "masculine" demeanor (e.g., yelling, angry outbursts) even more acceptable for men and less acceptable for women.

In summary, we propose that gender-role conforming behavior by perpetrators will be more expected and more accepted. In particular, behaviors associated with a lack of social competence and caring might elicit more negative moral judgments when they are performed by women. We also suggest that highly gendered behaviors may evoke gender-specific attributions regarding their cause and (emotional) controllability. As an exception, male-connoted behaviors involving physical violence and sexual harassment might still be judged as more severe when performed by men, as these behaviors might be perceived as less harmful when performed by female perpetrators.

\subsection{Third-Party Roles and Other Factors Influencing Moral Judgments}

The search for causality is also influenced by the beliefs and motivation of the perceiver [5]. HR professionals' rejection of bullying claims by targets has been linked to role dilemmas between being an "employee champion" and "strategic partner of management" in the capitalist, performance-driven Western business world [11,12,50]. Van Gramberg and Teicher [51] caution against viewing HR as an impartial party per se, since HR must represent the firm's interests; the role of employee representatives as "employee advocates" is likely to put more emphasis on targets' accounts. Moreover, interpretations may be influenced by the dominant organizational discourse on workplace bullying and organizational trainings.

For example, Skarlicki and Kulik [31] note that in sexual harassment cases third parties are encouraged to consider the "reasonable person standard" by explicitly adopting the victim's (usually female) perspective. Likewise, individual characteristics like a person's stage of moral development, moral and social identities (e.g., similarity with the perpetrator), and interactions with the other actors also affect attributions of blame, but are not the focus of this study [31].

\section{Materials and Methods}

\subsection{The Austrian Context}

This study based on interview data from Austrian HR professionals and employee representatives is part of an international project on bullying perceptions across different culture clusters worldwide based on the GLOBE culture dimensions [3,40]. Austrian HR professionals and employee representatives-more than third parties from other culturestend to conceptualize Mobbing am Arbeitsplatz as a "singling out" (peer) phenomenon 
involving subtle social exclusion and manipulation to strategically get rid of a certain person [3].

Austria has no anti-bullying legislation, which likely reduces awareness on the constitutive criteria of workplace bullying [3]. Employee representatives in organizations are part of the Austrian tradition of consensus-seeking between "labor" and "capital" (as opposed to confrontational measures like strikes, which are preferred in other countries) [52]. In Austria, works councils occupy one-third of seats on company boards. Similarly, participatory leadership and a team orientation are considered characteristics of outstanding leadership in the Germanic cultural cluster [41]. Consequently, negative behavior and workplace bullying of one's subordinates may be perceived as even less common and/or less acceptable than peer bullying. A relatively low gender egalitarianism index and high level of assertiveness practices [41] further characterize Austrian culture. This may make stereotypically masculine behaviors less acceptable when performed by women than by men.

\subsection{Interview Guide}

The second author of this study and a researcher partner developed the interview guide as part of a larger project. The guide consists of a list of various negative behaviors identified based on a review of frequently used, well-established questionnaires on workplace bullying [13,53]. The final list includes twelve different behaviors (work- and person-related, social exclusion/isolation, and overt aggression/intimidation).

All behaviors were formulated in active grammatical form. Informants were presented the twelve behaviors and asked if and why they regarded each behavior as (un)acceptable in specific work contexts in Austria; afterwards, we asked informants to explain whether and under which conditions they would label the behavior as Mobbing am Arbeitsplatz. Moreover, informants indicated whether it made a difference in their evaluation whether the behavior was performed by a superior, peer, or subordinate, and whether they perceived the behavior differently depending on whether a man or a woman performed it.

The semi-structured interview guide was translated into German by the first author, and back-translated into English by a German-English bilingual researcher. The twelve behaviors in English are listed below:

1. Spreading false rumors about someone or their work

2. Insulting someone or putting them down

3. Telling jokes or encouraging others to tell jokes about someone or engaging in practical jokes

4. Verbal abuse (e.g., yelling, cursing, angry outbursts)

5. Making aggressive or intimidating eye contact or physical gestures (e.g., pointing one's finger, slamming objects, obscene gestures)

6. Making unwanted physical contact (e.g., hitting, pushing, poking, spitting)

7. Giving tasks with unreasonable deadlines/assigning an unmanageable workload

8. Persistent criticism of errors or mistakes

9. Removing key areas of responsibility or replacing them with trivial or unpleasant tasks

10. Ignoring someone's opinion

11. Socially excluding or ignoring someone

12. Withholding necessary information from someone

\subsection{Sampling of Organizational Third Parties}

The first author conducted 27 semi-structured interviews with HR professionals (16) and employee representatives (11), including one expert from an Austrian trade union association. The sampling of informants was purposeful: while this is a qualitative study, we selected informants from industries with the highest numbers of employees in Austria in order to ensure that the most common organizational and sociocultural contexts were considered. We followed the principle of maximum variation [54] regarding company size. 
However, because professional HR departments and designated employee representatives tend to go along with a specific company size, most interview partners were from large companies with more than 500 employees in and around Vienna (Table 1). Employee representatives were employed as representatives either part-time or full-time ("exempted" from their original position). Most informants held a university degree, often in business or law (17). Ten interview partners were female and 17 were male. The informants' average age was 47 .

Table 1: Sample of interview partners.

Table 1. Description of the Sample.

\begin{tabular}{|c|c|c|c|c|c|c|}
\hline Pseudonym & Gender & $\begin{array}{l}\text { HRP or } \\
\text { ERP }\end{array}$ & $\begin{array}{c}\text { Highest Education of } \\
\text { Informant }\end{array}$ & $\begin{array}{l}\text { Approx. Number } \\
\text { of Employees }\end{array}$ & $\begin{array}{l}\text { Public/ } \\
\text { Private }\end{array}$ & $\begin{array}{l}\text { Industry Informant } \\
\text { is Working in }\end{array}$ \\
\hline Anna & $\mathrm{F}$ & Employee rep. & University & 1500 & Private & $\begin{array}{c}\text { Pharmaceutical } \\
\text { industry }\end{array}$ \\
\hline Bernhard & M & $\begin{array}{l}\text { Employee rep. } \\
\text { (part-time) }\end{array}$ & University & 850 & Private & Information services \\
\hline Christoph & M & HR professional & University & 2650 & Private & Paper production \\
\hline Dora & $\mathrm{F}$ & HR professional & University & 50 & Private & $\begin{array}{c}\text { Commercial cleaning } \\
\text { services }\end{array}$ \\
\hline Erwin & M & $\begin{array}{l}\text { Employee rep. } \\
\text { (part-time) }\end{array}$ & Apprenticeship & 325 & Private & Food retail \\
\hline Felix & M & HR professional & University & 1000 & Private & Food wholesale \\
\hline Gottwald & M & Employee rep. & $\begin{array}{c}\text { University entrance } \\
\text { qualification }\end{array}$ & 400 & Private & $\begin{array}{l}\text { Hospital/ } \\
\text { rehabilitation }\end{array}$ \\
\hline Hilde & $\mathrm{F}$ & HR manager & University & 320 & Public & Social insurance \\
\hline Ingrid & $\mathrm{F}$ & HR professional & $\begin{array}{c}\text { University entrance } \\
\text { qualification }\end{array}$ & 120 & Private & Construction \\
\hline Julia & $\mathrm{F}$ & HR Professional & University & 300 & Private & Call center \\
\hline Kathrin & $\mathrm{F}$ & $\begin{array}{l}\text { Employee rep. } \\
\text { (part-time) }\end{array}$ & University & 215 & Public & $\begin{array}{c}\text { Municipality (housing } \\
\text { office) }\end{array}$ \\
\hline Lore & $\mathrm{F}$ & HR professional & $\begin{array}{c}\text { University entrance } \\
\text { qualification }\end{array}$ & 210 & Private & Metalworking \\
\hline Michael & M & HR manager & University & 135 & Private & IT/Consulting \\
\hline Nelly & $\mathrm{F}$ & HR manager & University & 16,000 & Public & Municipality \\
\hline Otto & M & HR manager & University & 1150 & Private & Clothing production \\
\hline Peter & M & Employee rep. & $\begin{array}{c}\text { University entrance } \\
\text { qualification }\end{array}$ & 4000 & Public & Education \\
\hline Quentin & M & $\begin{array}{l}\text { Employee rep. } \\
\text { (part-time) }\end{array}$ & $\begin{array}{c}\text { University entrance } \\
\text { qualification }\end{array}$ & $>1000$ & Private & Tourism \\
\hline Richard & M & HR manager & University & $>5000$ & Private & Banking \\
\hline Stefan & M & HR manager & University & 650 & Private & Insurance services \\
\hline Thomas & M & HR professional & University & 3500 & Public & Social insurance \\
\hline Ulf & M & HR manager & $\begin{array}{c}\text { University entrance } \\
\text { qualification }\end{array}$ & 191 & Private & $\begin{array}{l}\text { Catering/ } \\
\text { Restaurant }\end{array}$ \\
\hline Veit & M & Employee rep. & Apprentice-ship & 3500 & Public & Social insurance \\
\hline Wilma & $\mathrm{F}$ & HR professional & University & 5000 & Private & Furniture retail \\
\hline Xerxes & M & HR manager & University & 800 & Private & IT \\
\hline Yuri & $\mathrm{M}$ & Employee rep. & University & 5000 & Public & Hospital \\
\hline Zeno & M & $\begin{array}{l}\text { Employee rep. } \\
\text { (part-time) }\end{array}$ & Apprenticeship & 500 & Private & Construction \\
\hline Aava (7 quest.) & F & $\begin{array}{l}\text { Employee } \\
\text { rep./Consultant }\end{array}$ & University & 2500 & Public & Trade union \\
\hline
\end{tabular}


All but one interview was conducted face to face (the interview with Otto was conducted via phone). Interviews lasted between $26 \mathrm{~min}$ and $1 \mathrm{~h} 18 \mathrm{~min}$; the average interview length was $50 \mathrm{~min}$. Interviews were transcribed in detail, meaning that minor utterances, laughter, pauses, etc. were also transcribed.

\subsection{Data Analysis}

We considered a summarizing qualitative content analysis to be most appropriate for the study purpose [55]. This method allows the amount of content to be reduced through paraphrasing and abstraction, but it never strays too far from the raw material. The prevalent themes and associations with negative behaviors were put into a categorization scheme. As such, the method lends itself to a "quantitative" overview and comparison of dominant themes/cues across categories [55].

In the first rounds of data analysis, the first author and a research assistant formed meaningful coding units from the raw data. After unitization, each unit was paraphrased. At this stage, both the first author and research assistant kept notes of their overall impressions of each informant's conceptualizations and patterns across behaviors.

Then, in a more detailed analysis, we coded each paraphrased unit [55]. Taking an inductive approach, the initial categories were not based on a prior theoretical concept; however, each interview question served as an initial unit for coding. Again, the researchers met frequently to compare their initial independent codes. Through continuous discussion and co-interpretation, we iteratively established coding rules for (ambiguous) categories. To ensure comparability, we aligned the category labels making up the final categorization scheme across behaviors (unless not applicable).

For example, to capture different degrees of moral acceptability, we formed the categories "unacceptable", "conditionally unacceptable", "conditionally acceptable", and "acceptable". The "unacceptable" category comprised units in which behaviors were (immediately) evaluated as unacceptable without any reasoning or with (fast) deontic responses (for example: "I cannot imagine that such a behavior could be acceptable in any organizational context"). If informants reasoned that a behavior was generally unacceptable but might be excusable under certain conditions (e.g., when there was no intent to harm), it was categorized as "conditionally unacceptable".

The respective subcategory then listed "intent to harm" as a criterion and attributional cue. Similarly, a behavior was categorized as "conditionally acceptable" if informants evaluated it as generally acceptable as long as certain conditions (e.g., criticism is justified by the target's performance). Similar categories were formed for the workplace bullying criteria ("workplace bullying", "conditionally bullying", "not bullying"). We also classified responses concerning perpetrators' social roles into different categories and subcategories across behaviors and further differentiated within each category whether informants drew on corresponding role expectations for perpetrators or other factors made a difference in perception. For example, we formed the category "hierarchical differences", which included subcategories such as "higher role expectations for supervisor" and "potentially more severe outcomes due to power differential" to describe responses where respondents perceived negative behaviors by a supervisor as more severe. The categorization scheme for perpetrator gender distinguished between whether informants found that gender stereotypes about what is the "common" or traditionally expected behavior affected perceptions (while often distancing themselves from the traditional views) or whether they engaged in gender stereotyping themselves. Also, other factors potentially affecting perceptions of misbehavior (e.g., the gender composition in the team) were kept as a separate subcategory.

We then considered the degree and form in which informants chose to make sense of each behavior and its (un)acceptability. We found that the type of behavior-rather than the perceiver's organizational role or other sample characteristics-evokes distinct criteria and attributional cues. We extracted three patterns of moral reasoning by comparing (prima facie) associations with behaviors and comparing the form and degree to which informants drew on specific attributional cues when evaluating a behavior and when labeling it as 
"workplace bullying". The different degrees of acceptability and the cue of malicious intent were particularly important for establishing the patterns.

\section{Results}

\subsection{Three (Moral) Reasoning Patterns}

We identified three reasoning patterns across behaviors, each of which involves a distinct degree of acceptability and distinct attributional cues and criteria: (1) "universally" unacceptable behaviors; (2) unacceptable behaviors with ambiguous intent or causal control; (3) conditionally acceptable behaviors caused by the target or the organization. Table A1 (Appendix A) provides an overview of the major findings for each behavior including the impact of the gender and hierarchical status of the perpetrator. The table will be explained in detail in the following subsections.

\section{2. "Universally" Unacceptable Bullying Behaviors}

The first reasoning pattern could be found across all behaviors, but most consistently with respect to "spreading false rumors about someone or their work", "withholding necessary information from someone" and "making unwanted physical contact".

In many cases, informants labeled a behavior as unacceptable prima facie. Negative moral judgments tended to come quickly and did not involve extensive justification or causal reasoning. This relates to the concept of "moral intuition" [8]. (Post-hoc) deontic reasoning included cues concerning moral intensity, usually a low social consensus and high magnitude of outcomes, and to a lesser degree the high probability and foreseeability of harm.

In particular with respect to spreading false rumors or withholding information, intent and harm were undisputable in the eye of many informants. This made the search for blame, alternative causes, and excuses for the perpetrator's behavior obsolete. Many informants associated these two behaviors with workplace bullying prima facie. Making unwanted physical contact or engaging in overt violence was often seen either as an extreme stage of workplace bullying or a unique type of assault.

Among professionals who had received training on this topic, these behaviors nevertheless only became workplace bullying if performed regularly and over a long period. This suggests that scientific definitions of workplace bullying have become institutionalized via trainings, and may "override" the moral intensity of a certain behavior.

The following excerpt from the interview with Gottwald (ERP, private hospital, 100 employees) on "spreading false rumors about someone or their work" shows how this behavior elicits quick moral judgments and associations with the intention to severely harm a target.

Interviewer: (...) spreading false rumours about someone or their work. Would this behaviour be considered acceptable in certain work contexts in Austria?

Gottwald: No, definitely not.

Interviewer: Why not?

Gottwald: It does not belong in the workplace. Starting and spreading rumours with the intention to harm or defame others are behaviours that do not belong in the workplace at all.

Interviewer: Ok, could this be called bullying?

Gottwald: One aspect of bullying, for sure. In my view telling untruths about someone is one characteristic of bullying.

\subsection{Ambiguous Intent or Causal Control}

The second pattern was predominantly but not exclusively found for "verbal abuse (yelling, angry outbursts etc.)", "insulting or putting someone down", "making aggressive eye contact or physical gestures", "ignoring someone's opinion", "socially excluding or ignoring 
someone", "giving tasks with unreasonable deadlines or assigning unmanageable workloads", and "telling jokes or encouraging others to tell jokes about someone or engaging in practical jokes".

The majority of informants applied quick deontic responses to these behaviors-at least initially. They framed these behaviors as highly unprofessional and with potentially severe outcomes, often due to the (public) denigration involved. However, these behaviors often also triggered a cognitive reasoning process in which the initially assumed agency and intent of the perpetrator were called into question. Here, informants often drew on their own experiences or gave hypothetical examples.

Examples included specific interaction patterns between actors in the workplace that might lead to high consensus and thus normalize specific rituals and (vulgar) practices in certain departments or masculine-typed cultures (in particular "practical jokes", "making aggressive eye contact or physical gestures", "verbal abuse"). Similarly, external pressure (e.g., a stressful work environment or time pressure) might excuse the perpetrator's conduct (especially "insulting or putting someone down", "verbal abuse", etc.). Likewise, uncontrollable reflexes/impulses (e.g., having a hot-tempered or insensitive personality) and thoughtlessness often reduced the perceived perpetrator agency (particularly for "socially ignoring or excluding someone", "ignoring someone's opinion", "insulting").

The individual behaviors within this pattern commonly required specific cues to be present in order to be labeled workplace bullying. Intentionality and repeated and/or long-term exposure were mentioned most often. Less frequently, distinctiveness (e.g., jokes aimed at one specific person, ignoring a specific person's opinion constantly) narrowed the range of possible explanations apart from intent to hurt the person.

The interview with Otto (HRP, private company in the textile industry, 1150 employees) illustrates how informants often needed to draw on additional information to evaluate the acceptability of ambiguous "contextual" behaviors unless they attributed intent.

Interviewer: Okay the next one: Telling jokes or encouraging others to tell jokes about someone or engaging in practical jokes. Would you consider this behaviour acceptable in certain work contexts in Austria?

Otto: If it is funny for everyone involved including the person addressed and if he [target] really considers it funny, too, and if it is appropriate in a situation and everyone has a laugh together, yes, it is okay. But, definitely, if you laugh at someone and he [target] doesn't find it funny at all (...) in that case it is not acceptable. If you really tell a joke with the intention to hurt and offend someone, and in this case the intention is crucial, it is unacceptable, and it is bullying.

\subsection{Conditionally Acceptable Behaviors Caused by the Target or Organization}

Two work-related behaviors were found to be (conditionally) acceptable and did not elicit deontic responses: "Persistent criticism of errors and mistakes" and "Removing key areas of responsibility or replacing them with trivial or unpleasant tasks."

The underlying cause and thus controllability of the perpetrator's behavior was often instantaneously attributed to the target (underperformance) or the situation (work requirements). However, informants mentioned at least one of the following conditions in order for the behavior to be rendered acceptable: a good reason, such as the target's low performance; the absence of malicious intent or "personal motives"; and conducting the behavior in a constructive manner (e.g., not criticizing the person in public).

Intent to harm was an important cue for the behavior to be labeled workplace bullying. Repetition was less often mentioned than in the other patterns, because "persistent criticism" already implied repetition and informants often considered "removing key areas of responsibility" to be a one-time activity. The reflection by Nelly (HR manager, municipal government, >1000 employees) is an example of how such behaviors often do not elicit moral awareness unless third parties attribute intent. 
Interviewer: Removing key areas of responsibility or replacing them with trivial or unpleasant tasks, for example. Is that acceptable for you in specific work contexts in Austria?

Nelly: That is acceptable, if it (.)/so it depends on the reason why I am doing it. If the supervisor does it because the employee is unable to cope with the task, is in over his/her head, then I have two options: either I let the employee do other tasks or I have to part with the employee. So that [behavior] can even be positive, by ensuring as a supervisor that I can deploy the person differently.

Interviewer: And could this be workplace bullying?

Nelly: Yes, again, if it is precisely this person who I am (...) excluding, i.e., where I have this end in mind.

\subsection{The Impact of the Perpetrator's Hierarchical Status}

When asked whether they would evaluate the behavior differently depending on the perpetrator's hierarchical status, most informants' answers concerned downward bullying. The informants rarely mentioned differences regarding peer bullying, let alone upward bullying. Only one informant (Richard) argued that the perpetrator's hierarchical status did not affect the perception of any behavior.

Overall, the third parties considered supervisory bullying more severe than peer and upward bullying. Only the two "acceptable" work-related behaviors-persistent criticism and removing key areas of responsibility - were perceived as more severe when exhibited by peers among a few informants, as such behaviors violate role expectations for peers. The behaviors making up the first two patterns elicited even stronger deontic responses by about half of informants when exhibited by supervisors, often due to rolemodel violations. However, the severity of behaviors within the first and second patterns often rendered the perpetrator's hierarchical status irrelevant in the informants' eyes, as Stefan (HR professional, private company in the insurance industry, $>350$ employees) illustrates:

Stefan: Again, totally terrible if a supervisor performs this behavior. But also among peers this is completely unacceptable.

The other half of informants mentioned the supervisor's higher (formal) power as well as harmful outcomes or potential sanctions against the target when the behavior is performed by a supervisor. Four employee representatives also considered the target less able to defend him- or herself against a variety of behaviors when performed by a supervisor rather than a peer, as the following example of "ignoring someone's opinion" from Veit (ERP, public hospital) demonstrates:

Interviewer: Does it make a difference who performs it [the behavior], a supervisor, a co-worker or a subordinate?

Veit: Well, a difference in the way of looking at it, yes surely it makes a difference. Because if the supervisor performs it/there again you have the question: How can I defend against it?" If a peer does it, I might be able to. [ . . ] With supervisors, this is more difficult for me; surely, that means I will be more likely to accept it.

There are exceptions to the findings discussed above. In some exceptional cases, "contextual" behaviors within the second pattern were regarded as more acceptable when conducted by a supervisor (e.g., ignoring someone's opinion, social exclusion). Some of these informants argued that, if anyone, a supervisor may perform this behavior.

\subsection{The Impact of the Perpetrator's Gender}

We asked informants whether they perceived each behavior differently depending on whether it was exhibited by a man or a woman. Eight out of 27 informants in our sample consistently perceived no gender differences in any behavior. However, many of these informants stressed that gender should not make a difference, or that the behavior itself was 
so unethical (see first pattern) that it did not matter who performed it. Moreover, hardly any perceived gender differences were mentioned for work-related behaviors.

The majority of the 18 informants who reported perceptual differences in at least one behavior referred to behaviors associated with a lack of social competence or anger (physical assaults, obscene threats or gestures, verbal abuse, insulting or putting someone down, practical and sexist jokes, ignoring someone's opinion). For example, 14 informants mentioned gender differences in perception for verbal abuse, which includes yelling and angry outbursts. Critical acknowledgements of the existence of traditional gender roles which bias perceptions and outcomes were predominant.

However, informants drew a subtle distinction when discussing the content of these behaviors: it was more expected that "common" aggressive masculine behaviors like yelling, making obscene gestures, or spitting would be performed by men in certain (maledominated) settings; nevertheless, these behaviors were also judged more harshly when performed by men because of the greater impact of men's physical and/or direct aggression. Hence, higher expectation and frequency did not make stereotypical aggressive behavior exerted by men appear more acceptable or less severe.

Moreover, the gender ratio in the organization or department was mentioned as relevant for the perception and evaluation of the above behaviors. For example, a practical or sexist joke against the only female member of a work group is perceived differently than in a gender-balanced environment. Furthermore, many informants claimed the same behavior was perceived differently if performed by women: not necessarily as more severe, but as more shocking or awkward. An example by Anna (ERP; private organization, $>1000$ employees) demonstrates this.

Interviewer: Would this behaviour be perceived differently if performed by a man versus a woman?

Anna: Of course. This is definitely a behaviour that is perceived differently. Cursing and yelling often seems more acceptable if performed by a man. I'll give you a typical example: a man who shouts at everybody around him and bangs his fists on the table is perceived as assertive whereas a woman acting in the same way is considered to be hysterical.

Interviewer: $\mathrm{Mm}-\mathrm{hm}$.

Anna: Yes, it is unfair, but that's the way it is.

Anna was one of eight informants who explicitly mentioned that (unexpected) behaviors performed by women involving dominance, physical aggression, or yelling and insulting were likely to be regarded as resulting from a malicious personality disposition or a personal vendetta (intent). For men, such behavior might be attributed to a stable and uncontrollable deficient personality disposition, such as insensitivity, thoughtlessness, egoism, or a lack of social competence.

While most of these informants critically reflected on these gender stereotypes, four (mostly male) informants from different educational and organizational backgrounds also stuck to existing stereotypes throughout the interview. Xerxes' (HR manager, private IT services company, 800 employees) interpretation of the behavior "insulting or putting someone down" is an example of this.

Xerxes: And also [men don't think about] the words they use. They insult. While women have the potential to be-my impression-yes, sensitive. And if they consciously and obviously insult, then it has a clear intention. So, the intention to hurt is greater if a woman does it. [With] a man, one first asks the question: Does he really want to hurt the other person, or did he not reflect. And just focused on himself."

\subsection{Third-Party Characteristics and Their Impact on (Moral) Reasoning}

Despite the qualitative nature of the study, we examined whether characteristics of our maximum variation sample might have affected our results. While, overall, HR professionals and employee representatives had similar moral attribution patterns, employee 
representatives more often referred to hierarchical power imbalances, i.e., the inability of the target to defend against supervisory bullying, than did HR professionals.

Informants with a university degree and those employed in large private or public companies ( $>500$ employees) more often indicated that they had received training on definitions and scientific criteria of workplace bullying in the past. Hence, alongside the previously identified patterns, highly skilled professionals who were aware of the scientific criteria for workplace bullying used them as primary attributional cues. They also often mentioned Leymann's criteria and categorization of behaviors [1] and argued that bullying is typically defined by a combination of behaviors.

Informants without a university degree often came from small- and medium-sized companies and had not received training, and were thus less consistent in their reasoning: They were more likely to unconditionally label various behaviors as bullying due to perceived harmful outcomes (e.g., psychological strain, feeling insulted) or strategic intent (to get rid of someone, to show someone that he/she is unwanted). Perceived lack of intent led to a denial of workplace bullying. Below, Ingrid (HRP, private construction company, 120 employees) reflects upon "making aggressive or intimidating eye contact or physical gestures":

\section{Interviewer: And could that be labelled as "workplace bullying"? Under (...).}

Ingrid: ( ... ) Puh. No, I do not think so. I think that is only a spontaneous (.)-If you are angry about something. A spontaneous gesture and one is not trying to put someone down over the long term.

\section{Discussion}

The overall aim of this study was to explore how (causal) attributions shape moral judgments and the labeling of diverse negative behaviors at work. The study corroborates earlier findings by showing that third parties differentiate between different types of negative behavior [56]. We explained these differences by showing that diverse behaviors elicit different degrees of moral awareness and distinct reasoning processes. With respect to perpetrators' social roles, we find that disconfirmation of role expectations due to both gender and hierarchical status affects moral evaluations of negative behaviors. Purely work-related behaviors were perceived as gender neutral by our informants.

The moral intensity of first-pattern behaviors such as withholding information or spreading rumors might have overshadowed possible gender effects. Moreover, social desirability might have influenced our interview partners' answers, as most were aware that gender should not make a difference in their perceptions. Timmers and colleagues [57] found in an experiment that respondents are reluctant to express or endorse stereotypically gendered beliefs concerning emotional behavior. When gender differences were mentioned, they concerned both the frequency and the acceptability of (non-conforming) role behavior by men and women.

Kelley and Michela [5] propose that disconfirmation of expected behavior results in causal attributions to the perpetrator's disposition rather than the situation. Some informants exhibited biases reflecting archetypal stereotypes about women, such as high sensitivity or an "innate" desire for personal vendettas. Likewise, excusing aggressive or insulting behavior by men as thoughtless, egotistical, and/or spontaneous aligns with stereotypes about men's aggression levels and lower self-control regarding anger-in other words, their relative lack of agency due to uncontrollable, stable factors. Prior studies on leadership have also found that the same domineering and assertive behavior is evaluated more negatively when performed by women [58].

In addition, the perceived ritualistic character of masculine-typed practices like practical jokes and screaming in specific work settings might make men appear less personally responsible for these behaviors. For example, male chefs' abusive work practices in commercial kitchens are often explained away as an expression of their artistic soul and leadership qualities [59]. Research on negative performance evaluations indicates that low performance by men receives more favorable causal attributions (e.g., bad luck), 
while women's failure is attributed to a lack of ability, particularly when the task is not "feminine" [60]. Such stereotypical causal attributions might affect third parties' moral judgments of misbehavior, but this requires further research.

Disconfirmation of perceived role expectations and moral obligations for supervisors led to high negative moral judgments and deontic reasoning. In contrast, mistreatment by peers and subordinates did not evoke anywhere near the same moral awareness among respondents. The participatory leadership norms, low power distance, and high performance orientation in the Germanic cultural cluster might make most negative behaviors by supervisors seem more morally reprehensible. As outlined above, gendered leadership norms highly affect the expression of misbehavior and need to be investigated in more detail in future studies.

Our broader results on attributional cues show that alongside repetition/long-term exposure, perceived intent was salient for labeling a given behavior as workplace bullying [14]. When a behavior is associated with full perpetrator agency, respondents often react with "moral intuition" and give deontic responses. Such high moral awareness and subsequent negative judgments are likely to motivate further action in organizational practice [61]. In contrast, the causal control, outcome, and intent of other behaviors are more ambiguous, which results in a search for other blame factors. Here, deontic reasoning does not necessarily guide third parties' sensemaking processes. Drawing upon Thiel et al. [62], we argue that an ethical decision-making process may not even be possible in ambiguous and complex situations.

Organizational third parties often lack first-hand information on the exact content of the behavior (e.g., content of the joke), actors' characteristics and interactions between them to engage in reasoning about the behavior. It thus comes as no surprise that such behaviors are made sense of as unacceptable or bullying only if they occur repetitively and/or with direct witnesses verifying the perpetrator's malicious intent [12]. Nevertheless, this could potentially lead to biased second-hand interpretations and responses. Violations of procedural or interactional justice (e.g., if persistent criticism is made without justification or in a destructive form) also raised (post-hoc) moral concerns among our informants.

However, it is important to note that many professionals in our sample were aware that perpetrators might use performance-related behaviors to engage in (subtle) bullying. Possible measures for increasing organizational awareness regarding such ambiguous behaviors include brochures and training that highlight the difference between legitimate negative feedback on (allegedly) low performance and workplace bullying.

Our findings reopen earlier discussions on whether to include the perpetrator's intent as a criterion for workplace bullying, as this factor strongly shapes bullying conceptualizations in organizational practice [34]. This clearly involves risks, as a perpetrator may easily deny any bad intention. Nevertheless, researchers applying quantitative surveys should keep in mind that popular items such as "spreading gossip and rumors about you" and "someone withholding information that affects your performance" (Negative Behaviors Questionnaire, Einarsen and colleagues [53]) are more likely to suggest intent and causal control compared to items such as "being confronted with an unmanageable workload" and may thus affect respondents' perceptions. Active vs. passive grammatical forms also have moral implications, as the former highlights perpetrator agency, whereas the latter focuses on the behavior's effect on targets.

Overall, contrary to our initial expectations, we did not find substantial differences between the conceptualizations of HR professionals and employee representatives. The Germanic "consensus" model might make role dilemmas between "labor" and "capital" within organizations less pronounced [52]. Another interpretation is that this occurred because informants were discussing negative behaviors and workplace bullying on a general level. Our results also indicate that HR managers' tendency to deny bullying might not (only) relate to their organizational role as a strategic partner of management [12,50], but (also) to the moral outrage each behavior causes. However, a difference between the roles was employee representatives appeared more sensitive to the inability to defend 
against negative behaviors in a subordinate position. Real-life cases may shed more light on the impact of third party roles, in particular on how to respond and intervene in cases with formal power differences (employees as targets and supervisors as bullies). (Quasi-) experimental designs with fictional bullying cases, where the perpetrator's hierarchical status is manipulated, may also shed more light on differences in responses by employee representatives in their role as "employee advocates" and HR professionals as strategic partners of management. Also, further training, in particular for HR professionals, on the effect of power differentials for targets' responses can increase awareness and effective organizational intervention. Training on the negative economic effects of WP bullying for all workforce members and the whole organization might also be effective to increase awareness on WP bullying among (HR) management.

In addition, our results indicate that informants from large public companies were particularly likely to be aware of the scientific criteria for workplace bullying and Heinz Leymann's [1] understanding of workplace bullying as systematic behavioral patterns excluding someone from the workplace. These findings demonstrate how practitioners' conceptualizations of workplace bullying are shaped by the dominant (scientific) discourse in a country and its dissemination through workshops and trainings.

It is important to note potential limitations of our study. This interview study was intended to conceptualize and explore primary (moral) attribution patterns among organizational third parties when confronted with a negative behavior. In organizational practice, contextual information and actor-specific information may affect attributions. Furthermore, real-life targets may exhibit a combination of behaviors, potentially overshadowing the relevance of any specific behavior. Moreover, Austria's high performance orientation and the connotation of the German term "Mobbing am Arbeitsplatz" as a strategic group phenomenon involving the singling out of one person [3] make our findings less generalizable to non-German speaking countries.

Lastly, the impact of gender or other characteristics of organizational third parties on attributions deserve to be studied in more detail than was possible with our sample size and methodological approach. Future studies should address this topic through approaches such as quasi-experimental scenario designs in which perpetrator gender is manipulated.

Author Contributions: Conceptualization, E.Z. and D.S.; Methodology, E.Z. and D.S.; Software, E.Z.; Validation, E.Z.; Formal analysis: E.Z.; Investigation: E.Z. and D.S.; Resources, E.Z. and D.S.; Data curation, E.Z.; Writing—original draft preparation, E.Z.; Writing—review and editing: D.S.; Visualization, E.Z.; Project administration, D.S. and E.Z.; Funding acquisition, D.S. and E.Z. All authors have read and agreed to the published version of the manuscript.

Funding: This study was funded by the Academy of Finland (grant numbers 266294 and 308843) and by the Austrian Chamber of Labour.

Institutional Review Board Statement: The study was conducted according to the guidelines of the Declaration of Helsinki and the ethical guidelines of the universities involved. Ethical review and approval were waived for this study, as the study did not fall into any of the categories requiring ethical review board approval at the universities in question.

Informed Consent Statement: Informed consent was obtained from all subjects involved in the study.

Data Availability Statement: Not applicable.

Conflicts of Interest: The authors declare no conflict of interest. 


\section{Appendix A}

Table A1. Overview on third-party responses and the impact of gender and hierarchical status on moral judgments.

\begin{tabular}{|c|c|c|c|c|}
\hline Behavior & Acceptability of Behavior & Criteria for WP Bullying & $\begin{array}{c}\text { Behavior Perceived } \\
\text { Differently If Performed } \\
\text { by Men vs. Women? }\end{array}$ & $\begin{array}{c}\text { Does Hierarchical Status } \\
\text { of Perpetrator Affect } \\
\text { Evaluations? }\end{array}$ \\
\hline $\begin{array}{l}\text { 1. Spreading false rumors } \\
\text { about someone or their } \\
\text { work }\end{array}$ & universally unacceptable & Intent & Gender irrelevant & $\begin{array}{l}\text { Irrelevant due to high } \\
\text { moral intensity/more } \\
\text { severe if performed by } \\
\text { supervisor }\end{array}$ \\
\hline $\begin{array}{l}\text { 2. Insulting someone or } \\
\text { putting them down }\end{array}$ & $\begin{array}{l}\text { ambiguous intent or } \\
\text { causal control }\end{array}$ & $\begin{array}{l}\text { Intent, Repetition, } \\
\text { Distinctiveness }\end{array}$ & $\begin{array}{c}\text { Gender can make a } \\
\text { difference }\end{array}$ & $\begin{array}{c}\text { More severe or acceptable } \\
\text { if performed by } \\
\text { supervisor }\end{array}$ \\
\hline $\begin{array}{l}\text { 3. Telling jokes or } \\
\text { encouraging others to tell } \\
\text { jokes about someone or } \\
\text { engaging in practical jokes }\end{array}$ & $\begin{array}{l}\text { ambiguous intent or } \\
\text { causal control }\end{array}$ & $\begin{array}{l}\text { Intent, Repetition, } \\
\text { Distinctiveness }\end{array}$ & $\begin{array}{c}\text { Gender can make a } \\
\text { difference }\end{array}$ & $\begin{array}{c}\text { More severe if performed } \\
\text { by supervisor }\end{array}$ \\
\hline $\begin{array}{l}\text { 4. Verbal abuse (e.g., } \\
\text { yelling, cursing, angry } \\
\text { outbursts) }\end{array}$ & $\begin{array}{l}\text { ambiguous intent or } \\
\text { causal control }\end{array}$ & Intent, Repetition & $\begin{array}{l}\text { Gender can make a } \\
\text { difference }\end{array}$ & $\begin{array}{c}\text { More severe or acceptable } \\
\text { if performed by } \\
\text { supervisor }\end{array}$ \\
\hline $\begin{array}{l}\text { 5. Making aggressive/ } \\
\text { intimidating eye contact, } \\
\text { physical gestures } \\
\text { (pointing finger, obscene } \\
\text { gestures) }\end{array}$ & $\begin{array}{l}\text { ambiguous intent or } \\
\text { causal control }\end{array}$ & Intent, Repetition & $\begin{array}{c}\text { Gender can make a } \\
\text { difference }\end{array}$ & $\begin{array}{c}\text { More severe if performed } \\
\text { by supervisor }\end{array}$ \\
\hline $\begin{array}{l}\text { 6. Making unwanted } \\
\text { physical contact (e.g., } \\
\text { hitting, pushing, poking, } \\
\text { spitting) }\end{array}$ & universally unacceptable & Intent & $\begin{array}{c}\text { Gender can make a } \\
\text { difference }\end{array}$ & $\begin{array}{c}\text { More severe if performed } \\
\text { by supervisor }\end{array}$ \\
\hline $\begin{array}{l}\text { 7. Giving tasks with } \\
\text { unreasonable } \\
\text { deadlines/assigning an } \\
\text { unmanageable workload }\end{array}$ & $\begin{array}{l}\text { ambiguous intent or } \\
\text { causal control }\end{array}$ & Intent, Repetition & Gender irrelevant & $\begin{array}{c}\text { Can only be performed by } \\
\text { supervisor }\end{array}$ \\
\hline $\begin{array}{l}\text { 8. Persistent criticism of } \\
\text { errors or mistakes }\end{array}$ & conditionally acceptable & $\begin{array}{l}\text { Intent, Repetition, Public } \\
\text { Ridiculing }\end{array}$ & Gender irrelevant & $\begin{array}{c}\text { More severe if performed } \\
\text { by peers }\end{array}$ \\
\hline $\begin{array}{l}\text { 9. Removing key areas of } \\
\text { responsibility or replacing } \\
\text { them with trivial or } \\
\text { unpleasant tasks }\end{array}$ & conditionally acceptable & Intent & Gender irrelevant & $\begin{array}{c}\text { Can only be performed by } \\
\text { supervisor }\end{array}$ \\
\hline $\begin{array}{l}\text { 10. Ignoring someone's } \\
\text { opinion }\end{array}$ & $\begin{array}{l}\text { ambiguous intent or } \\
\text { causal control }\end{array}$ & $\begin{array}{l}\text { Intent, repetition, } \\
\text { distinctiveness }\end{array}$ & $\begin{array}{c}\text { Gender can make a } \\
\text { difference }\end{array}$ & $\begin{array}{c}\text { More severe or acceptable } \\
\text { if performed by } \\
\text { supervisor }\end{array}$ \\
\hline $\begin{array}{l}\text { 11. Socially excluding or } \\
\text { ignoring someone }\end{array}$ & $\begin{array}{l}\text { ambiguous intent or } \\
\text { causal control }\end{array}$ & Intent & $\begin{array}{c}\text { Gender can make a } \\
\text { difference }\end{array}$ & $\begin{array}{l}\text { More severe if performed } \\
\text { by peers }\end{array}$ \\
\hline $\begin{array}{l}\text { 12. Withholding necessary } \\
\text { information from someone }\end{array}$ & universally unacceptable & Intent & Gender irrelevant & $\begin{array}{l}\text { Irrelevant due to high } \\
\text { moral intensity/more } \\
\text { severe if performed by } \\
\text { supervisor }\end{array}$ \\
\hline
\end{tabular}

\section{References}

1. Leymann, H. The content and development of mobbing at work. Eur. J. Work Organ. Psychol. 1996, 5, 165-184. [CrossRef]

2. Notelaers, G.; van der Heijden, B.; Hoel, H.; Einarsen, S. Measuring bullying at work with the short-negative acts questionnaire: Identification of targets and criterion validity. Work Stress 2019, 33, 58-75. [CrossRef]

3. Salin, D.; Cowan, R.; Adewumi, O.; Apospori, E.; Bochantin, J.; D’Cruz, P.; Djurkovic, N.; Durniat, K.; Escartín, J.; Guo, J.; et al. Workplace bullying across the globe: A cross-cultural comparison. Pers. Rev. 2019, 48, 204-219. [CrossRef]

4. Thirlwall, A. Organisational sequestering of workplace bullying: Adding insult to injury. J. Manag. Organ. 2015, 21, 145-158. [CrossRef]

5. Kelley, H.; Michela, J. Attribution theory and research. Annu. Rev. Psychol. 1980, 31, 457-501. [CrossRef]

6. Weiner, B. Attribution theory. Int. Encycl. Educ. 2010, 6, 558-663.

7. Haidt, J. The emotional dog and its rational tail: A social intuitionist approach to moral judgment. Psychol. Rev. 2001, 108, 814-834. [CrossRef] [PubMed]

8. Escartín, J.; Rodríguez-Carballeira, A.; Zapf, D.; Porrúa, C.; Martín-Peña, J. Perceived severity of various bullying behaviours at work and the relevance of exposure to bullying. Work Stress 2009, 23, 191-205. [CrossRef]

9. Hewett, R.; Liefooghe, A.; Visockaite, G.; Roongrerngsuke, S. Bullying at work: Cognitive appraisal of negative acts, coping, wellbeing, and performance. J. Occup. Health Psychol. 2018, 23, 71-84. [CrossRef] 
10. Zapf, D.; Escartín, J.; Einarsen, S.; Hoel, H.; Vartia, M. Empirical Findings on Prevalence and Risk Groups of Bullying in the Workplace. In Bullying and Harassment in the Workplace: Developments in Theory, Research, and Practice, 2nd ed.; Einarsen, S., Hoel, H., Zapf, D., Cooper, C.L., Eds.; Taylor \& Francis: Boca Raton, FL, USA, 2011; pp. 75-105.

11. Harrington, S.; Warren, S.; Rayner, C. Human resource management practitioners' responses to workplace bullying: Cycles of symbolic violence. Organization 2015, 22, 368-389. [CrossRef]

12. Cowan, R.L. It's complicated: Defining workplace bullying from the human resource management professional's perspective. Manag. Commun. Q. 2012, 26, 377-403. [CrossRef]

13. Fox, S.; Owan, R. Revision of the workplace bullying checklist: The importance of human resource management's role in defining and addressing workplace bullying. J. Hum. Resour. Manag. 2015, 25, 116-130. [CrossRef]

14. Saunders, P.; Huynh, A.; Goodman-Delahunty, J. Defining workplace bullying behavior professional lay definitions of workplace bullying. Int. J. Law Psychiatry 2007, 30, 340-354. [CrossRef]

15. Mawdsley, H.; Thirlwal, A. Third-party interventions in workplace bullying: A neoliberal agenda? Empl. Relat. 2019, 41, 506-519. [CrossRef]

16. Willemsen, P.; Newen, A.; Kaspar, K. A new look at the attribution of moral responsibility: The underestimated relevance of social roles. Philos. Psychol. 2018, 31, 595-608. [CrossRef]

17. Koenig, A.; Eagly, A. Evidence for the Social Role Theory of Stereotype Content: Observations of Groups' Roles Shape Stereotypes. J. Personal. Soc. Psychol. 2014, 107, 371-392. [CrossRef]

18. Treviño, L.K.; Weaver, G.W.; Reynolds, S.J. Behavioral ethics: A review. J. Manag. 2006, 32, 951-990.

19. Jones, T.M. Ethical decision making by individuals in organizations: An issue-contingent model. Acad. Manag. Rev. 1991, 16, 366-395. [CrossRef]

20. Folger, R.; Skarlicki, D.P. Beyond counterproductive work behavior: Moral emotions and deontic retaliation versus reconciliation In Counterproductive Work Behavior: Investigations of Actors and Targets; Fox, S., Spector, P.E., Eds.; American Psychological Association: Washington, DC, USA, 2005; pp. 83-105.

21. Pizarro, F.; Uhlmann, E.; Bloom, P. Causal deviance and the attribution of moral responsibility. J. Exp. Soc. Psychol. 2003, 39, 653-660. [CrossRef]

22. Greene, J.; Morelli, S.A.; Lowenberg, K.; Nystrom, L.E.; Cohen, J.D. Cognitive load selectively interferes with utilitarian moral judgment. Cognition 2008, 107, 1144-1154. [CrossRef]

23. Malle, B.; Guglielmo, S.; Monroe, A.E. A Theory of Blame. Psychol. Inq. 2014, 25, 147-186. [CrossRef]

24. Alicke, M. Culpable control and the psychology of blame. Psychol. Bull. 2000, 126, 556-574. [CrossRef]

25. Cushman, F. Deconstructing intent to reconstruct morality. Curr. Opin. Psychol. 2015, 6, 97-103. [CrossRef]

26. Driver, J. Attributions of causation and moral responsibility. In Moral Psychology, Vol. 2. The Cognitive Science of Morality: Intuition and Diversity; Sinnott-Armstrong, W., Ed.; MIT Press: Cambridge, UK, 2008; pp. 423-439.

27. Shaver, K.G. The Attribution of Blame, Causality, Responsibility, and Blameworthiness; Springer: New York, NY, USA, 1985.

28. Greene, J.; Haidt, J. How (and where) does moral judgment work? Trends Cogn. Sci. 2002, 6, 517-523. [CrossRef]

29. Weiner, B. Social Motivation, Justice, and the Moral Emotions: An Attributional Approach; Lawrence Erlbaum Associates Publishers: Mahwah, NJ, USA, 2006.

30. Ferris, G.; Bhawuk, D.; Fedor, D.; Judge, T. Organizational politics and citizenship: Attributions of intentionality and construct definition. In Attribution Theory: An Organizational Perspective; Martinko, M., Ed.; St. Lucie Press: Delray Beach, FL, USA, 1995; pp. 231-252.

31. Skarlicki, D.P.; Kulik, C. Third-party reactions to employee (mis)treatment: A justice perspective. In Research on Organizational Behavior; Staw, B.M., Kramer, R.M., Eds.; JAI Press: Greenwich, CT, USA, 2005; Volume 26, pp. 183-230.

32. Leslie, A.M.; Knobe, J.; Cohen, A. Acting Intentionally and the Side-Effect Effect. Psychol. Sci. 2006, 17, 421-427. [CrossRef] [PubMed]

33. Rahimi, S.; Hall, N.C.; Pychyl, T.A. Attributions of responsibility and blame for procrastination behavior. Front. Psychol. 2016, 7, 11-79. [CrossRef]

34. Malle, B.F. Attribution theories. How people make sense of behavior. In Theories in Social Psychology; Chadee, D., Ed.; WileyBlackwell: West Sussex, UK, 2011; pp. 72-95.

35. Samnani, A.; Singh, P.; Ezzedeen, S. Workplace bullying and employee performance: An attributional model. Organ. Psychol. Rev. 2013, 3, 337-359. [CrossRef]

36. van Kleef, G.; Lange, J. How hierarchy shapes our emotional lives: Effects of power and status on emotional experience, expression, and responsiveness. Curr. Opin. Psychol. 2020, 33, 148-153. [CrossRef]

37. Howard, J.L.; Johnston, A.C.; Wech, B.A.; Stout, J. Aggression and Bullying in the Workplace: It's the Position of the Perpetrator that Influences Employees' Reactions and Sanctioning Ratings. Empl. Responsib. Rights J. 2016, 28, 79-100. [CrossRef]

38. Hoyt, C.L.; Terry, L.P.; Poatsy, L. The Social Role Theory of Unethical Leadership. Leadersh. Q. 2013, 24, 712-723. [CrossRef]

39. Haidt, J.; Baron, J. Social roles and the moral judgement of acts and omissions. Eur. J. Soc. Psychol. 1996, 26, 201-218. [CrossRef]

40. Parzefall, M.R.; Salin, D. Perceptions of and reactions to workplace bullying: A social exchange perspective. Hum. Relat. 2010, 63, 761-780. [CrossRef]

41. House, R.J.; Hanges, P.M.; Dorfman, P.; Gupta, V. Culture, Leadership and Organizations. The GLOBE Study of 62 Societies; Sage: Thousand Oaks, CA, USA, 2004. 
42. Sloan, M. Controlling Anger and Happiness at Work: An Examination of Gender Differences. Gend. Work Organ. 2012, 19, 370-391. [CrossRef]

43. Brescoll, V.L. Leading with their hearts? How gender stereotypes of emotion lead to biased evaluations of female leaders. Leadersh. Q. 2016, 27, 415-428. [CrossRef]

44. Ellemers, N. Gender stereotypes. Annu. Rev. Psychol. 2018, 69, 275-298. [CrossRef]

45. Shields, S.A.; MacArthur, H.J.; McCormick, K.T. The gendering of emotion and the psychology of women. In American Psychological Association Handbook on the Psychology of Women; Travis, T., White, J.W., Eds.; American Psychological Association: Washington, DC, USA, 2017; pp. 189-206.

46. Mackey, J.; Martinko, M.J. The role of gender and attributional style in counteproductive aggressive work behaviors. In Gender and the Dysfunctional Workplace; Fox, S., Lituchy, T., Eds.; Edward Elgar: Cheltenham, UK; Northhampton, UK, $2012 ;$ pp. 43-61.

47. Arutyunova, K.R.; Alexandrov, Y.I.; Hauser, M.D. Sociocultural Influences on Moral Judgments: East-West, Male-Female, and Young-Old. Front. Psychol. 2016, 7, 1334. [CrossRef] [PubMed]

48. Plant, E.A.; Hyde, J.S.; Keltner, D.; Devine, P.G. The gender stereotyping of emotions. Psychol. Women Q. 2003, 24, 81-92. [CrossRef]

49. Grubb, A.; Turner, E. Attribution of blame in rape cases: A review of the impact of rape myth acceptance, gender role conformity and substance use on victim blaming. Aggress. Violent Behav. 2012, 17, 443-452. [CrossRef]

50. Ulrich, D. Human Resource Champions; Harvard Business School: Boston, MA, USA, 1997.

51. van Gramberg, B.; Teicher, J. Managing neutrality and impartiality in workplace conflict resolution: The dilemma of the HR manager. Asia Pac. J. Hum. Resour. 2006, 44, 197-210. [CrossRef]

52. Szabo, E.; Brodbeck, F.; den Hartog, D.N.; Reber, G.; Weibler, J.; Wunderer, R. The Germanic cluster: Where employees have a voice. J. World Bus. 2002, 37, 55-68. [CrossRef]

53. Einarsen, S.; Hoel, H.; Notelaers, G. Measuring exposure to bullying and harassment at work: Validity, factor structure and psychometric properties of the Negative Acts Questionnaire-Revised. Work and Stress 2009, 23, 24-44. [CrossRef]

54. Patton, M. Designing Qualitative Studies: Qualitative Evaluation and Research Methods; Sage: Beverly Hills, CA, USA, 1990; pp. 169-186.

55. Mayring, P. Qualitative Inhaltsanalyse, Grundlagen und Techniken, 10th ed.; Beltz Verlag: Weinheim, Germany; Basel, Switzerland, 2008.

56. Neuberger, O. Mobbing: Übel Mitspielen in Organisationen; Hampp: München, Germany, 1999.

57. Timmers, M.; Fischer, A.H.; Manstead, A.S.R. Ability versus vulnerability: Beliefs about men's and women's emotional behavior. Cogn. Emot. 2003, 17, 41-63. [CrossRef]

58. Koenig, A.; Eagly, A.; Mitchell, A.; Ristikari, T. Are leader stereotypes masculine? A meta-analysis of three research paradigms. Psychol. Bull. 2011, 137, 616-642. [CrossRef]

59. Bloisi, W.; Hoel, H. Abusive work practices and bullying among chefs: A review of the literature. Int. J. Hosp. Manag. 2008, 27, 649-656. [CrossRef]

60. Foschi, M. Gender, performance level, and competence standards in task group. Soc. Sci. Res. 2009, 38, 447-457. [CrossRef] [PubMed]

61. Rest, J.R. Moral Development: Advances in Research and Theory; Praeger: New York, NY, USA, 1986.

62. Thiel, C.; Bagdasarov, Z.; Harkrider, L.; Johnson, J.; Mumford, M. Leader ethical decision-making in organizations: Strategies for sensemaking. J. Bus. Ethics 2012, 107, 49-64. [CrossRef] 